\title{
Removal Of Methylene Blue From Aqueous Solution By Bio-Adsorbent Pouch
}

\author{
Muhammad Zharif Jasni ${ }^{1}$, Nor Hakimin Abdullah ${ }^{2}$, Mohd Sukhairi Mat Rasat ${ }^{2}$, Khairul Nizar \\ Syazwan Wan Salihin Wong' ${ }^{2}$ Mohamad Faiz Mohd Amin ${ }^{1 *}$ \\ \{moh.ahmadfaiz@gmail.com*\} \\ ${ }^{1}$ Faculty of Earth Science (FSB), Universiti Malaysia KelantanKampus Jeli, Locked Bag 100,17600 \\ Jeli, Kelantan, Malaysia \\ ${ }^{2}$ Advanced Material Research Cluster, Faculty of Bioengineering and Technology, Universiti Malaysia \\ Kelantan Kampus Jeli, Locked Bag 100,17600 Jeli, Kelantan, Malaysia
}

\begin{abstract}
Study of dye removal by using activated carbon in dialysis tube method was studied in order to determine the effectiveness of this method. Three different parameters namely activated carbon dosage, temperature and contact time were evaluated. Characterization of the activated carbon was realized by Scanning electron microscopy (SEM) to observe the morphology of the activated carbon. Based on the obtained results, the performance of the activated carbon in the presence of dialysis tubing method was explained.
\end{abstract}

Keywords: Activated Carbon, Bio-adsorbent, Dye Removal, Dialysis Tube, Methylene Blue.

\section{Introduction}

The bio-adsorbent pouch used in this research consist of sawdust based commercial activated carbon and dialysis tube. The activated carbon used was in a powdered form to enable maximum adsorptive capabilities. Activated carbon considered as a member of a family of carbons which range from carbon blacks to nuclear graphites, from carbon fibres and composites to electrode graphites, and numerous more (Marsh and Rodríguez-Reinoso, 2006). Coal is considered as an importantand well-known carbon source in activated carbon production (Arsyadet al, 2016). Carbon made from biomass can also be a source of energywhich can be obtain from agricultural, forestry and livestock residues (Ahmad et al., 2015; Rasat et al., 2016; Sirrajudin et al., 2016).Also, there are several studies that focused on renewable energy obtained from carbon made from biomass (Ahmad et al., 2016, 2017).Every carbon has its own unique identity and it will affect their porosity and characteristics. However, the quality and consistency of activated carbon is determined by the sources and quality of the coal or parent material (Arsyad et al., 2016). The carbonization of the parent material will produce structures that can be considered as segments of graphene sheets with different sizes that can reach nanometer dimensions and degree of perfection, bonded together with an infinite number of ways (Marsh and Rodríguez-Reinoso, 2006). The porosity is then multiplied by further development through activation process after carbonization process takes place (Bansal\&Goyal, 2005).Activation process of activated carbon involves the surface modification of carbon surface by activating agent where it happens at the molecular level (Abdullah et al, 2015).

Dialysis tube is widely used in medicinal propose of hemofiltration and also in heavy metal filtration. As example, a study of chromium removal had showed a positive result which indicate that dialysis tubing would not only useful for detoxification of chromate, but also 
useful in removal of total chromium from water (Komori et al., 1990).The dialysis tube works by allowing certain molecules with the size smaller than its pores to pass through the membrane. However, several factors may affect its efficiency such as the temperature, $\mathrm{pH}$, viscosity, stirring rate, membrane area and even liquid volume of the solutions(Meyer and Guttman, 1970). By combining these traits from dialysis tubing with activated carbon adsorption abilities, the capabilities of both factors to work synergistically were observed in this study.

\section{Materials And Methods}

\subsection{Materials}

Commercial activated carbon was supplied by TakeItGlobalSdn. Bhd. (Malaysia) as the adsorbent. Methylene Blue as adsorbate was obtained from Capetra Resources (Malaysia) and used without further purification. Purified water used in this study was prepared in the laboratory. The dialysis tube used in this study was obtained from Sigma-Aldrich with average flat width of $32 \mathrm{~mm}$ (1.3 inch), MWCO 12400, and 99.9\% retention.

\subsection{Methods}

\subsubsection{Preparation of Stock Solution}

$0.1 \mathrm{~g}$ of methylene blue powder was weighted using electronic balance and mix with $20 \mathrm{ml}$ distilled water. Then, the solution was poured into a $1 \mathrm{~L}$ beaker and filled with distilled water until reached $1 \mathrm{~L}$ mark. The beaker was put on magnetic stirrer and stirred until the methylene blue completely dissolved.

\subsubsection{Preparation of Cellulose Dialysis Tubing}

The dialysis tube was kept in a distilled water overnight to remove the wax. Then, it was cut into $5 \mathrm{~cm}$ length each.

\subsubsection{Calibration Curve}

The stock solution was diluted into $5,4.5,4.0,3.5,3.0,2.5,2.0,1.5,1.0$ and $0.5 \mathrm{mg} / \mathrm{L}$ and analyzed using UV-Vis Spectrophotometer to obtain the absorbance of each concentration. The calibration curve was made using the data obtained and the $\mathrm{R}^{2}$ was calculated using Microsoft Excel software.

\subsubsection{Scanning Electron Microscopy (SEM)}

Scanning Electron Microscopy was used to observe the structures and morphologies of the activated carbon used. The image of the structures was observed at x750 magnification.

\subsubsection{Adsorbent Dosage}

Dosages of $0.2,0.4,0.6,0.8,1.0 \mathrm{~g}$ of activated carbon was prepared in dialysis tubing and placed in a $250 \mathrm{ml}$ conical flask with $200 \mathrm{ml}$ of $5 \mathrm{mg} / \mathrm{L}$ methylene blue for 3 hours in an orbital shaker with $150 \mathrm{rpm}$ rotation speed. The conical flasks were put in the orbital shaker with $150 \mathrm{rpm}$ rotation speed. The solution was tested using UV-Vis Spectrophotometer at the end of the experiment. 


\subsubsection{Temperature}

Five different temperatures of solution were used to study its effects to the percentage of dye removed. The dialysis tubing containing $0.2 \mathrm{~g}$ activated carbon was left in $200 \mathrm{ml}$ of 5 $\mathrm{mg} / \mathrm{L}$ Methylene Blue solution with30, 40, 50, 60 and $70{ }^{\circ} \mathrm{C}$ temperaturesfor 3 hours in an orbital shaker with $150 \mathrm{rpm}$ rotation speed. The solutions were tested using UV-Vis Spectrophotometer to obtain the absorbance at the end of the experiment.

\subsubsection{Contact Time}

The percentage of dye removed was studied for a specific time period by leaving the dialysis tubing with $0.2 \mathrm{~g}$ activated carbon in $200 \mathrm{ml}$ solution of $5 \mathrm{mg} / \mathrm{L}$ Methylene Blue for several hours in an orbital shaker with $150 \mathrm{rpm}$ rotation speed. Aliquots of solution was taken each 30 minutes to be examined using UV-Vis Spectrophotometer.

\section{Results And Discussion}

A wavelength of $662.0 \mathrm{~nm}$ obtained after analyzing the methylene blue solution prepared using the UV-Vis spectrophotometer. Calibration curve was plotted for each experiment to obtained the desired equation in calculation of dye concentration to be used in the calculation of percentage dye removal as seen in Figure 1. Each experiments includes the agitation process to enhance the rate of diffusion by the dialysis tubing and activated carbon adsorption. The increase of rate of diffusion can be caused by the agitation of the solution which tends to homogenize the concentrations of the solutions (Meyer and Guttman, 1970).

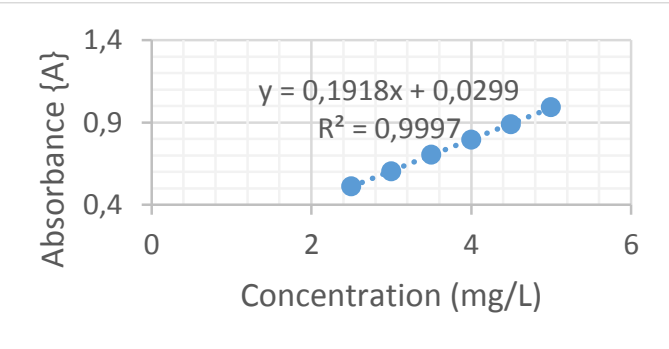

Fig.1. Calibration Curve

\subsection{Scanning Electron Microscopy (SEM)}

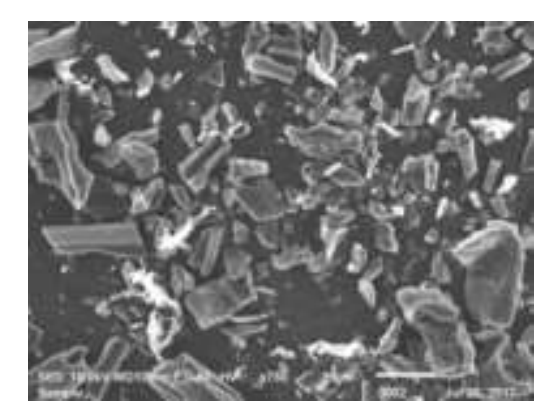

Fig.2. SEM image of activated carbon at $20 \mu \mathrm{m}$ 
SEM has been a main tool in the process of characterizing the surface morphology and fundamental physical properties of the adsorbent surface (Mahmoodi, Salehi and Arami, 2011). It is useful for determining the particle shape, porosity and appropriate size distribution of the adsorbent. From Figure 2, the image observed shows the structures of the activated carbon used. The small structure contributed to the large surface area which increases the adsorption rate of dye. Figure 2 shows the image of considerable amount of pores which can trap the dye molecules in adsorption process.

\subsection{Effect of Adsorbent Dosage}

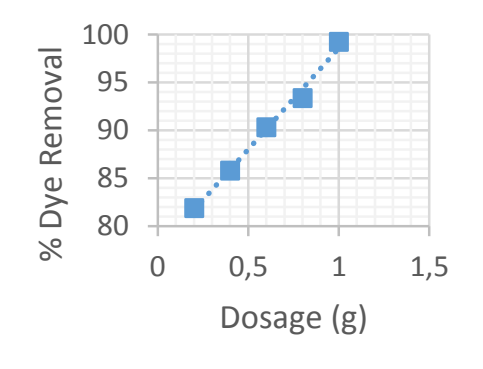

Fig.2. Percentage of dye removal for different dosage of activated carbon used

Different percentage of dye removal was obtained after using three different dosage of activated carbon. Based from Figure 4, the percentage of dye removal increased as the dose of activated carbon increased. Similar findings had been reported in the treatment of organic contaminant (Ademiluyi, Amadi and Amakama, 2010) and dye removal (Garg et al., 2004; Khaled et al., 2009; Mahmoodi, Salehi and Arami, 2011). The increment percentage of dye removal increases as the dose increase due to the improvement and availability of active surface area and additional adsorption sites (Garg et al., 2004; Khaled et al., 2009; Mahmoodi, Salehi and Arami, 2011). The activated carbon used was in powder form which efficiently provides the surface area needed in adsorption capacity. Figure 3 also shows that $1 \mathrm{~g}$ of activated carbon can adsorb up to $5 \mathrm{mg} / \mathrm{L}$ of methylene blue in 3 hours with the presence of cellulose dialysis tubing. The presence of dialysis tubing did not interrupt the adsorption process by the activated carbon and still allow the rate of adsorption increases proportionally to its dosage.

\subsection{Effect of Temperature}




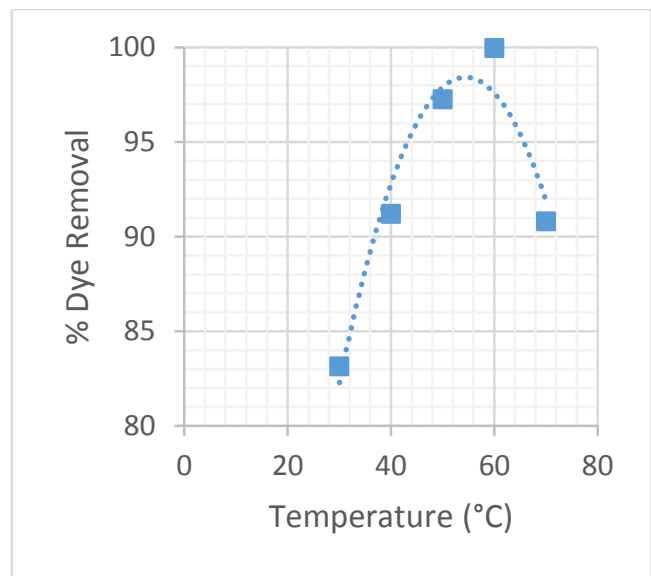

Fig.4. Percentage of dye removal in different temperature

Figure 4 shows the dye removal percentage increased as the temperature of the solution increased in three hours of agitation. The same finding was reported in the removal of Congo red using activated carbon prepared from coir pith (Namasivayam and Kavitha, 2002). From observations, it is believed that as the temperature increased, the pore of the dialysis tubing membrane will enlarge and destabilize which enables the dye to diffuse faster. The increase of the percentage of dye removal proved that there was indeed an increased in the rate of diffusion. However, the percentage of dye removal decreasedat $70{ }^{\circ} \mathrm{C}$ which showed that it exceeded the optimum temperature for the rate of diffusion. Similar studies indicated the importance in temperature control to prevent any negative effect of temperature on the intrinsic dialytic rate of the small molecule through the membrane (Meyer and Guttman, 1970).

\subsection{Effect of Contact Time}

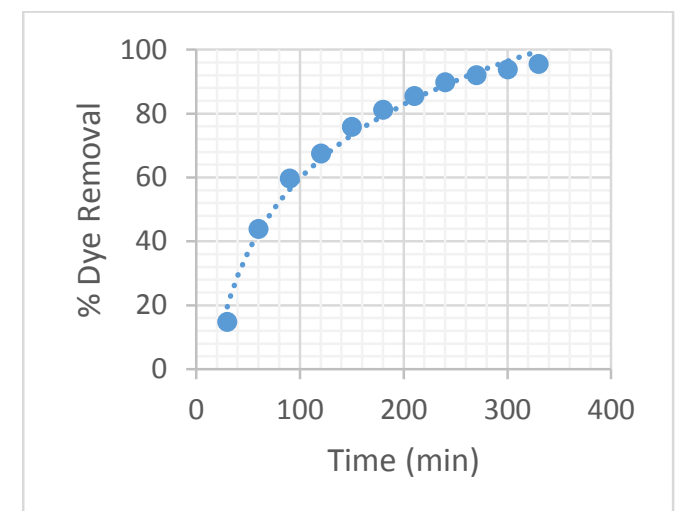

Fig.5. Percentage of dye removal in three hours

From Figure 5, it can be observed that the percentage of dye removal increased gradually but slowly decreased towards the end.Some studies showed a similar result where removal of dye increased as the contact time increased and it stopped to a certain extent. It might be due tothe disposition of dyes on the existing adsorption site on adsorbent material (Khaled et al., 
2009; Ansari and Mosayebzadeh, 2010; Radaei, Alavi Moghaddam and Arami, 2014).According to Malik, 2004, the dye will firstly travel through the solution exterior surface of the adsorbent particles by molecular diffusion such as film diffusion, then followed by the movement of solute from particle surface into the interior site by pore diffusion, which ends by the adsorbed of the dye into the active site at the interior of the adsorbent particles.

\section{Conclusion}

The SEM image shows a high surface area of the activated carbon with the presence of considerable amount of pores. The dialysis tube methodshowed that each variable affects the percentage of dye removal. The presence of dialysis tube was found to be facilitated the dye removal process management.These findings would be useful for future designing of wastewater treatment for various organic contaminants.

\section{Acknowledgement}

The authors gratefully acknowledge the Ministry of Higher Education, Malaysia in support of this study through the Niche Research Grant Scheme (NRGS)R/NRGS/A07.00/00303A/002/2014/000151 and SGJP UMK.PC/B01.08.11/600$5 / 2 / 3(133)$.

\section{Reference}

[1] Ademiluyi, F., Amadi, S. and Amakama, N. (2010) 'Adsorption and Treatment of Organic Contaminants using Activated Carbon from Waste Nigerian Bamboo.', Journal of Applied Sciences and Environmental Management, 13(3). doi: 10.4314/jasem.v13i3.55351.

[2] Ahmad, M. I. et al. (2015) 'Performance and carbon efficiency analysis of biomass via stratified gasifier', ARPN Journal of Engineering and Applied Sciences, 10(20), pp. 9533-9537.

[3] Ahmad, M. I. et al. (2016) 'Preliminary Study of Microwave Irradiation Towards Oil Palm Empty Fruit Bunches Biomass', 4, pp. 133-137.

[4] Ahmad, M. I. et al. (2017) 'The effect of Torrefaction on Oil Palm Empty Fruit Bunch Properties Using Microwave Irradiation', Journal of Fundamental and Applied Sciences, 9(3S), pp. 924-940.

[5] Ansari, R. and Mosayebzadeh, Z. (2010) 'Removal of Basic Dye Methylene Blue from Aqueous Solutions Using Sawdust and Saedust Coated with Polypirrole', J. Iran. Chem. Soc., 7(2), pp. 339-350. doi: 10.1007/BF03246019.

[6] Arsyad, N. A. S. et al. (2016) 'Effect of Chemical Treatment on Production of Activated Carbon from Cocos nucifera L . ( Coconut) Shell by Microwave Irradiation Method', International Journal of Electroactive Materials, 4(1), pp. 729-738. doi: $10.4103 / 0973-8398.76742$.

[7] Garg, V. K. et al. (2004) 'Basic dye (methylene blue) removal from simulated wastewater by adsorption using Indian Rosewood sawdust: A timber industry waste', Dyes and Pigments, 63(3), pp. 243-250. doi: 10.1016/j.dyepig.2004.03.005.

[8] Khaled, A. et al. (2009) 'Removal of Direct N Blue-106 from artificial textile dye effluent using activated carbon from orange peel: Adsorption isotherm and kinetic studies', Journal of Hazardous Materials, 165(1-3), pp. 100-110. doi: 
10.1016/j.jhazmat.2008.09.122.

[9] Komori, K. et al. (1990) 'A method for removal of toxic chromium using dialysis-sac cultures of a chromate-reducing strain of Enterobacter cloacae', Applied Microbiology and Biotechnology, 33(1), pp. 117-119. doi: 10.1007/BF00170582.

[10] Mahmoodi, N. M., Salehi, R. and Arami, M. (2011) 'Binary system dye removal from colored textile wastewater using activated carbon: Kinetic and isotherm studies', Desalination. Elsevier B.V., 272(1-3), pp. 187-195. doi: 10.1016/j.desal.2011.01.023.

[11] Marsh, H. and Rodríguez-Reinoso, F. (2006) Characterization of Activated Carbon, Activated Carbon. doi: 10.1016/B978-008044463-5/50018-2.

[12] Meyer, M. C. and Guttman, D. E. (1970) 'Dynamic dialysis as a method for studying protein binding. I. Factors affecting the kinetics of dialysis through a cellophane membrane.', Journal of pharmaceutical sciences, 59(1), pp. 33-8. doi: DOI 10.1002/jps.2600590104.

[13] Namasivayam, C. and Kavitha, D. (2002) 'Removal of Congo red fromwater by adsorption onto activated carbon prepared from coir pith,an agricultural solid waste', Dyes Pigments, 54, pp. 47-58.

[14] Radaei, E., Alavi Moghaddam, M. R. and Arami, M. (2014) 'Removal of reactive blue 19 from aqueous solution by pomegranate residual-based activated carbon: optimization by response surface methodology.', Journal of environmental health science \& engineering, 12(1), p. 65. doi: 10.1186/2052-336X-12-65.

[15] Rasat, M. S. M. et al. (2016) 'Preliminary study on properties of small diameter wild Leucaena Leucocephala species as potential biomass energy sources', ARPN Journal of Engineering and Applied Sciences, 11(9), pp. 6128-6137.

[16] Sirrajudin, M. S. et al. (2016) 'Enhancing the energy properties of fuel pellets from oil palm fronds of agricultural residues by mixing with glycerin', ARPN Journal of Engineering and Applied Sciences, 11(9), pp. 6122-6127. 